\title{
Do Methods of Estimantion Affect Credit Risk Oscillations?
}

\author{
Dmitry Vladimirovich Burakov
}

Financial University under the Government of Russian Federation

Email:dbur89@yandex.ru

\section{Doi:10.5901/mjss.2014.v5n20p114}

\begin{abstract}
In this article we study the relationship between methods of estimation and dynamics of credit risk. Based on the analysis of statistical time series of loans granted and overdue debts in US banking sector for the period of over 100 years, as well as using experimental settings, we find evidence that evolution of credit risk evaluation methods does not contribute to reducing the amplitude of credit market fluctuations, as well as does not reduce the level of credit risk accepted by lenders. Moreover a hypothesis, according to which innovations in credit risk management increase the willingness to accept risk, gains additional support.
\end{abstract}

Keywords: credit risk; credit cycle; credit market; framing; anchoring; bounded rationality; behavioral economics

\section{Introduction}

The events of the last two decades in the global financial system have challenged the theoretical notions of economic system's development, its stability and a role of the credit market in achieving this goal. All of these theoretical propositions make the basis of the neoclassical economic thought. The primary and dominant view about the causes of recurring crisis events is the poor quality of risk management in credit sphere, and in particular, credit risk management. In other words, most researchers believe that the main cause of the recent crisis may be found in excessively accumulated, and, subsequently, realized, risks in the banking system. (Burakov, 2014b)

Even taking into account the accumulated experience, the Basel Committee on banking supervision continues to assert that the main goal of "Basel III" is "strengthening regulation, supervision and risk management in banking", by means of achievement of several objectives, including, among others "improvement of the ability of the banking sector to absorb shocks arising in connection with financial and economic frictions, regardless of the source; improving risk management and control".

In our opinion, a theoretical inconsistency in the Basel Committee's provisions exists. On the one hand, it is proposed to develop methods and tools for assessing credit risk, due to their lack of predictive power. On the other one it's proposed to implement instruments of countercyclical regulation (e.g., provisions, capital buffer) - as recognition of the inability to cope with the excessive growth of credit risk burden on the credit market. In defense of the Basel Commitee, one can argue about the coexistence of the risk on the one hand, and uncertainty, on the other, under which market players have to make decisions. (Burakov, 2013) This argument removes the contradiction, partially. If one would ask about the hierarchy of the objectives of regulation (containment of the crisis or mitigation of its consequences), it is clear that the Basel Committee does not give a definite answer.

However, we believe that credit risk management is the task of the first level, because timely reduction of pressure on the market will reduce the probability of credit market overheating and large-scale implementation of the crisis event.

To confirm this statement, one should refer to the theory of credit dynamics, in particular, to the theory of the credit cycle, allowing disclosing the ynamics of credit risk.

Firstly, it should be noted that the fundamental core of the credit cycle is the dynamics of credit risk. (Burakov, 2014c; Burakov, 2014d) The upward phases of the cycle are characterized by the process of expansion of credit activity and accumulation of credit risk. The transition point from the upward phases to downward ones is the phenomenon of a specific nature (internal or external). Downward phases of the cycle are characterized by the process of credit supply reduction and realization of accumulated credit risk. Scale (amplitude) of credit risk oscillations on the downward phases depends on the nature of the credit cycle.

Secondly, the cyclical movement of credit holds sustainable in most countries at periods over 150 years. (Haldane, 2010) This provision leads us to the conclusion about stability of oscillations not only in the movement of supply and 
demand for credit, caused by the shocks of exogenous and endogenous nature, but also on the stability of cyclical motion of credit risk.

Thus, it can be assumed that the stability in the development of the credit market is directly connected with the management of the cyclical movement of credit. In other words, timely controlling the credit expansion will directly affect the level of credit risk accepted by the banking organizations. (Barth et.al, 2008)

In proposals of the Basel Committee on banking supervision fulfillment of this task is assigned to the "improvement of risk assessment techniques". In our opinion, this approach will not bring the desired effect due to the fact that the theoretical basis of the documents developed by the Committee is the paradigm of neoclassical school of economics, which is absolutely inconsistent with the realities of economic relations. "Basel III" (and previous versions) does not take into account one of the most important provisions of the modern economic theory, which is the statement of bounded rationality of subjects, which has depicted as its theoretical viability so as the practical relevance.

This disadvantage is, in our opinion, is not as significant as determines the necessary directions for developing proposals upon improvement of the regulation of the banking sector in order to ensure its stable development. This theoretical weakness generates the purpose of our study which is to determine the potential impact of credit risk evaluation methods on the dynamics of credit risk.

The achievement of this goal is connected with solution of a number of tasks. First, it's necessary to determine whether the improvement of evaluation methods helps in reducing credit risk accepted in the long run; second, we try to determine whether methods of credit risk evaluation represent a factor hindering the cyclical fluctuations of credit risk; third, we try to understand how does perception of the risk's estimation using quantitative/qualitative methods correlates with the willingness to take risk, depending on the phase of the credit cycle?

\section{Literature Review}

This section looks at the evolution of credit risk management theory, reveals main historical stages of development of risk assessment theory and its methods'. Also key approaches to determine the role of risk management in banking sector are pointed out.

\subsection{Evolution of risk manangement theory in credit market}

Credit risk is an inherent feature of credit relations carried out in conditions of risk and uncertainty. One of the first references about the existence of the borrower's default probability on a granted loan and its legal definition may be found in the code of Hammurabi (1750s BC). Even then default on the loan was considered a crime and demanded an appropriate punishment, identical for theft and fraud. Originally credit relationships were to be built upon interpersonal agreements of the lender and the borrower. And a significant role in these relations was played by mutual trust and reputation of the counterparties.

Until the second half of the XIX century a so-called qualitative approach prevailed in the methods of credit risk assessment. Credit analysis was built on the availability of personal information about each borrower and the conditions of the local market.

Due to economic development, complication of economic relations, expansion of local and national markets and their relationship, the information requirements began to strengthen (for example, in case when the distance between the bank, granting loans, and the borrower, railway company, constituted a significant barrier to determine the creditworthiness).

In the USA, for example, specific information about the quality of railway tracks and personal qualities of managers now began tp play a significantly smaller role than the volume of cargo transportation rates and the overall cost level of railway company functioning. Unfortunately, to get access to such information directly from the company in those days was very difficult, due to lack of unified requirements and strict control over validity and reliability of the financial statements. In such conditions prototypes of the modern rating agencies that provided to subscribers commercial information of organizations throughout the United States began to emerge. (Brown, 2004). The first agency in the United States that provided such a service, was "Dun \& Bradstreet", founded in 1841. One of the innovations that led to the formation of the modern foundations of credit risk analysis was the decision by John Moody to merge such product as the credit report of "Dun \& Bradstreet" with the investment review published "Standard \& Poor's". However, due to lack of reliable data to assess the probability of borrower's default, ratings remained predominantly qualitative, and were presented in the form of expert judgment. For the railway sector historical financial data was of a fragmentary and unreliable nature, and for all other industries - data was almost absent. 
In those days, the railway companies were leaders in creation and development of departments for statistical analysis.(Cunningham, 1911) Use of statistical data (so called, credit "barometrics") was considered by practitioners and theorists, as an innovation that can reduce credit risks.(Dewey\&Shugrue, 1922; Kavanaugh 1921) The appearance of this innovation owes a lot to the creation of the Federal Reserve System, which tightened requirements for credit relations. Prior to this, the provision of financial statistics, including balance sheet and income statements by borrowers was not required. Moreover, this kind of information was considered a commercial secret, and the relationship between creditor and borrower was based on mutual trust and assessment of personal qualities. (Kavanaugh 1921)

Thus, one of the main problems on the way of development of quantitative methods of risk assessment was the lack and/or unavailability of information, suitable for the construction of time series.

The first attempts to use structured quantitative approach in the methods of credit risk assessment appear in the late 50's - early 60's of the XX century. In 1973 the model of Black-Scholes was first presented. In 1980s a standardized method for evaluating borrowers' quality, based on a point system (credit scoring) was developed; in the late 1980s, after the collapse of the U.S. stock market in 1987, the first version of the regulatory principles of the Basel Committee was created; in the mid 1990's JP Morgan develops the first internal model for the assessment of credit risk - "CreditMetrics" that was the impetus for distribution of VaR analysis methods, used in the banking sector to this day. (Dione,2013)

As one can see, the development of risk assessment techniques in most cases was seen as a way to reduce information asymmetry in credit relations, and, therefore, improve the quality of decisions made under the credit agreements. In other words, leading representatives of the economic and credit thought, as well as experts and banking community for over 100 years, argues that the development of risk evaluation methods promoted and continues to promote the reduction of risks taken by players on the credit market. (Brown, 2004)

\subsection{Behavioral economics on models of credit risk assesment}

An alternative view upon the place and role of the methods of credit risk assessment is offered by proponents of rapidly developing "revolutionary camp" of behavioral school of economics. Late 90's of the XX century was the time of heated debates on the issue of innovations in risk management. Particuclarly there was a strong controversy over the efficiency of using $\mathrm{VaR}$ analysis as a tool to measure credit risk. These debates continue to this day. For example, the criticism of Taleb (2009) boils down to two main arguments: first, the definition of the risk's "dead zone" (the tail risk) is not possible, due to the vague nature of market environment; second, the use of VaR as a tool of analysis in conditions of bounded rationality leads to taking excessive risks in connection with the existence of the anchoring effect.

Support of the provision about the ambiguity of quantitative methods of risk analysis themselves and periods of their introduction (innovations in the sphere of risk management) can be found in works of another behavioral economist T. Rötheli. (Rötheli, 2013) According to his hypothesis, introduction of new methods of credit risk analysis in the U.S. in the early XX century, on the one hand, increased the level of risks taken in the credit market, on the other, such innovations acted as an anchor, strengthening overconfidence effect - factor of reinforcement in a positive outcome on granted loans (new methods of analysis were perceived as a panacea for poor borrowers). On the basis of historical analysis, Rötheli comes to the conclusion that innovations in credit risk evaluation methods contributed to an increase in the level of credit risks accepted and in competition on the credit market.

So, there is a discussion about the role and place of credit risk assessment methods in the fulfilment of their direct tasks. Proponents of the mainstream economics proceed from the necessity of further improvement of evaluation methods, while representatives of the heterodox schools warn against excessive reliance on methods of risk assessment and remind that the decision, when using any methods, is made by a person whose rationality is far from full.

In this article we set ourselves a task to determine if evolution of credit risk's evaluation methods actually contributes to reducing the level of risks taken by lenders; also we test the hypothesis, according to which innovations in credit risk management enhance risk seeking behavior.

\section{Research Methodology}

\subsection{Time series analysis and correlation tests}

In this study, we set ourselves a task to define the relationship between methods of credit risk assessment, their evolution and realized losses. To answer this question, we refer to the of time series of annual growth rates of loans granted by commercial banks in the USA, the share of overdue debt in the total volume of loans, the volume and dynamics of writeoff losses s for the periods of 1896-2012, 1922-2012. Unequivocal assessment of credit risk is possible only ex post. 
Proceeding from the assumption that credit risk is the core of fluctuations in credit activity, it can be assumed that the reduction of fluctuations in credit activity is the result of a decrease in accumulated and implemented risks in connection with the improvement of the quality of their assessment and forecasting.

The sampling period should be sufficient so as to include stages characterizing various approaches to the analysis of credit risk. If the approach to risk assessment and risk assessment methods have an impact in the long term on the overall quality of the credit market, it is logical to assume that with the development of approaches and methodsof risk management, the oscillation amplitude of credit activity and debt losses must diminish. In this study the stages of the evolution of approaches to credit risk management are defined as follows: 1 - qualitative approach to the analysis of credit risk, 2 - protoquantitative approach, 3 - quantitative approach

\subsection{Experimental setting: participants and design}

184 students, 103 males and 81 females, from three faculties of Financial University under the Government of Russian Fedetation were invited to participate in the study. The average age was 22.43 years ranging from 18 to 24 years old. The participants varied greatly in terms of the length of their learning experience, and acquired competences during their education process. The mean years of learning experience was 3.12 with a standard deviation 1.27 from the mean.

The instrument used in this study was the questionnaire, designed to determine the impact of the variable in contrast to the control group.

For experimental setting to be unbiased at most, it was necessary to make a number of assumptions based on which one could determine the role of risk assessment methods in theoretical terms.

Assumption 1. The risk evaluation method (qualitative/quantitative) is a reinforcement factor of confidence in the outcome of the credit relations.

Assumption 2. The subject, making a decision on granting the loan (hereinafter - the creditor) is characterized by bounded rationality.

To determine the impact of credit risk assessment methods on changes (oscillations) in relation to the credit risk, we used experimental research methods.

We have developed an experimental framework in order to clarify the differences in reaction to the credit risk depending on the applied method of analysis.

In the case of qualitative analysis methods (control group), respondents (sample amounted to 184 people) were invited to make the following decision in the format of "Yes/No" questions:

"Are you willing to extend credit to the borrower on the basis of the following information: 1) the borrower is familiar to you personally and is characterized as honest, responsible and purposeful manager; 2 ) his rate of return of loaned funds for the last 3 years is $98,7 \%$; 3 ) $1.3 \%$ of no retuhis defaults was associated with external conditions and touched $85 \%$ of all your borrowers".

To reflect the quantitative methods (condition group) of risk analysis, experemintal framework was changed:

"Are you willing to grant a loan to the borrower on the basis of the following information: 1) his rate of return on earlier loaned funds over the last 3 years is $98,7 \%$; 2) $1.3 \%$ of defaults were associated with external conditions and touched $85 \%$ of all your borrowers; 3 ) for the last year his assets rose by $25 \%$ and net profit by $20 \% "$ ", 4) the rest of your borrowers on average increased assets by $7 \%$, net profit - by $9 \%$ per year"

Third setting included the opportunity to make a decision based on qualitative quantitative methods of assessment strengthened by personal experience (experience group):

"Are you willing to extend credit to the borrower on the basis of the following information: 1) his rate of return of loaned earlier funds for the last 3 years is $88,7 \%$; 2 ) in your opinion, the market is overheated."

Fourth setting included the opportunity to make a decision based both on the personal experience and results of the quantitative methods of analysis (cumulated effect group):

"Are you willing to extend credit to the borrower on the basis of the following information: 1) his rate of return of loaned earlier funds for the last 3 years is $88,7 \% ; 2$ ) according to the data of the quantitative analysis of the implemented program "IMetrics" the possibility of return of money loaned is $95,7 \%, 4$ ) in your opinion, the market is overheated." 


\section{Findings and Discussion}

\subsection{Results of the statistical time series ananlysis}

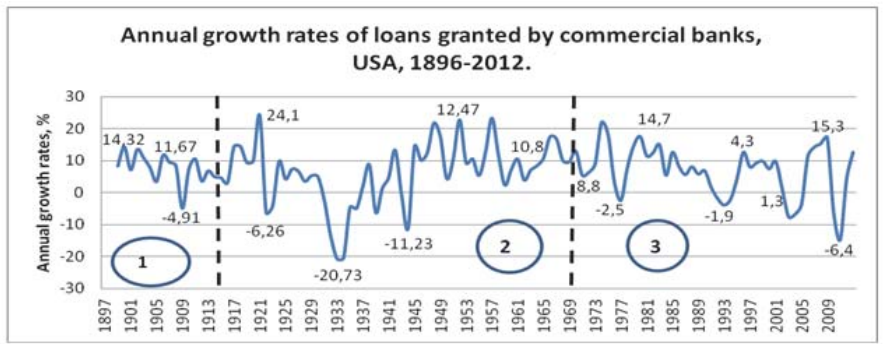

Figure 1. Annual Growth Rates of Loans granted by Commercial Banks, USA, 1896-2012.

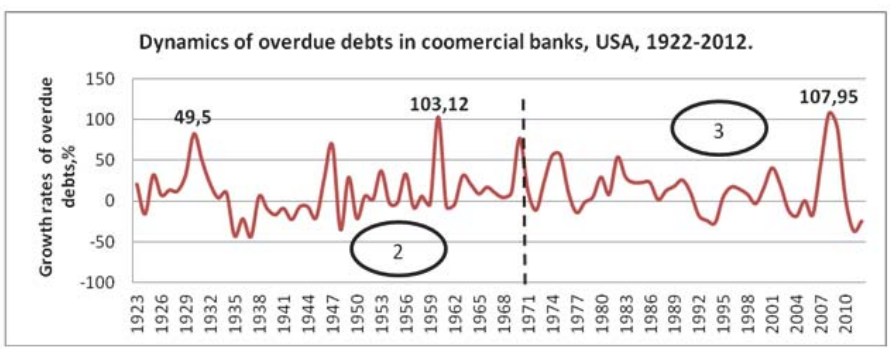

Figure 2. Dynamics of Overdue Debts in Commercial Banks, USA, 1922-2012.

As can be seen from Fig.1,2 changes in approaches to the analysis of credit risk had no significant impact neither on amplitude of fluctuations in credit dynamics, nor the volume of loan losses. For example, the average of credit growth rates (in the upward phase of the credit cycle) in stage 1 was 8,32\%, on the second - 10,31\%, the third - 9,8\%. Thus, the assertion about the limiting role of credit risk assessment methods in the accumulation of credit risk is seen as irrelevant to reality.

Data presented in Figure 2 also does not endorse the provisions of the mainstream thought on the issue.Data of the dynamic series clearly shows that the growth rate of written-off losses and overdue debts in the latest crisis is several times higher than the rate of growth of losses written off during the Great Depression. Average dynamics for write-off losses for stage 1 (qualitative methods of credit risk evaluation) is $8,89 \%$, while in the period of active dissemination of quantitative methods of evaluation (scoring model in the 1980s, the VaR analysis in the 1990s) average of loans write-off almost doubled and reached $15,76 \%$. We should add, that data on the share of overdue debts in the total portfolio of loans also validate statistics presented above. According to the Federal Reserve System of USA, the peak of overdue debts during the Great Depression (1934) was 2.5\% from all loaned funds. While during the Great Recession peak of arrears (2009) these measures amounted to $3.5 \%$.

Thus, the statistics allow us to answer the first two questions which we set above. Firstly, the evolution of methods of credit risk assessment does not contribute to the reduction of the level credit risks taken in the long run (based on the data of development of the credit market in the USA). Secondly, methods of credit risk assessment are not a deterrent to cyclical fluctuations of credit risk.

\subsection{Results of experemintal study}

The results of the first survey (control group) were as follows: in the first survey, $11 \%$ of respondents chose the answer "No", 89\% answered "Yes"; in the second survey (condition group), the answer "Yes" selected $88.5 \%$ of respondents; answer "No" - $11.5 \%$.

Thus, we can assume that the change of methods of analysis of the borrower's quality does not have a significant 
impact on the attitude toward credit risk. However, in the case of amendments of some other methods and factors of reinforcement there appears a cumulative effect, which ultimately leads to the growth of confidence in a positive outcome, and, consequently, to the increase of the level of credit risk taken: the results of the third survey (experience group) were as follows $83 \%$ of respondents chose the answer "No", 17\% answered "Yes".

Based on these results we can assume that personal intuition and experience is a well established and inherent anchor which serves as one of the main back-up factors when building confidence in the outcome under risk and uncertainty. (Tversky\&Kahneman, 1981).

The last experimental setting (cumulated effect group) was designed to counterpose different anchors in decisionmaking. One anchor (intuition and experience) opposed another (results of quantitative credit risk evaluation). In the last survey, the answer "Yes" was chosen by $39 \%$ of respondents, answer "No" - 61\%. So we can assume that relying on quantitative methods is actually a kind of psychological anchor, which increases the confidence in the positive outcome, as well as in the negative one depending on the phase of the credit cycle. (Burakov, 2014a).

Proceeding from the results, we can assume that the theoretical assumptions of behavioral economists about the anchoring effect in respect to the credit risk are viable. (Tversky\&Kahneman, 1974) Formalization of credit relations, accounting for only the current experience with the borrower, as well as on data of quantitative assessment reinforce the willingness to accept credit risk. It is important to remember that this increase exists as on the upward phase of the credit cycle so as on the downward ones. On the upward phases of the cycle willingness to accept credit risk increases, while on a downward phase, willingness to take risks reduces.

\section{Concluding Remarks}

In the result of the research we have identified and supported by different kinds of arguments some very significant positions in the theory of credit dynamics and credit risk. Unlike the conventional approach to the theory of credit risk, we start from the theory of bounded rationality of decision-makers. The proposals of the Basel Committee on banking supervision regarding improvement of efficiency of credit risk as a tool to achieve stable development of the credit market are questioned.

In the result of this study new findings are received and the existing theoretical assumptions are confirmed.

First, given the results of historical and statistical analysis, with the weighted confidence we can say that the evolution of methods of credit risk assessment has not brought significant results neither in the reduction of amplitude of credit risk oscillations, nor in reducing the overall level of credit risks taken by commercial banks onn the credit market in thelong-term (on the example of the USA), nor in reducing cyclical fluctuations of credit risk.

In other words, perfection of methods of credit risk assessment should not be not a priority and the main goal, the achievement of which will allow to provide the best quality and stability in development of the credit market.

Secondly, through the use of experimental methods of research, we found evidence reinforcing theoretical principles of the behavioral school of economics, according to which, methods and tools of risk assessment are only the reinforcement factor of confidence in the outcome and cannot be considered in isolation from the bounded rationality of the subjects.

Thirdly, we proposed and substantiated the hypothesis upon the effects of bounded rationality on the perception, assessment and attitude toward the methods of credit risk evaluation:

1. bounded rationality of decision-makers does not have a significant impact on the perception of credit risk evaluation results by different methods. The results of the experiment on quantitative and qualitative methods did not reveal significant differences in impact on the formation of preferences toward credit risk. This is due to the lack of innate ability to comprehend percentages by human psychic. In other words, this is a consequence of the indifference effect also known as uncertainty aversion;

2. bounded rationality of subjects affects the attitude toward credit risk in case when the qualitative methods are supplemented by quantitative ones and they begin to serve as an anchor in decision making process;

3. the cumulative effect of using these two methods as a reinforcement factor of confidence in the outcome has an impact on the general frame in which decision is made: on the downward phase of the cycle, the use of these methods will serve as a proof of necessisty to reduce risk level (perhaps even too reduce), and on the phase of credit expansion, on the contrary - to promote excessive accumulation of credit risk. 


\section{References}

Barth, J.R., Caprio, G., Levine, R. (2008). Rethinking Bank Regulation: Till Angels Govern. Cambridge University Press.

Brown, A.(2004). The Origins and Evolution of Credit Risk Management. GARP Review, September-October, pp. 1-3.

Burakov, D.V. (2013). Exogenous Credit Cycle: An Experimental Study. World Applied Sciences Journal, 26(6), pp. 733-736.

Burakov, D.V. (2014a). Does Framing Affect Risk Attitude? Experimental Evidence from Credit Market. American Journal of Applied Sciences, 11, pp. 391-395.

Burakov, D.V. (2014b). Limited Liability, Bank Capital and Credit cycles. A Behavioral Economic Approach. Middle East Journal of Scientific Research, 21(1), pp. 28-32.

Burakov, D.V. (2014c). Propagation Mechanism of Credit Risk in the Credit Cycle. European Journal of Social Sciences, 41(4), pp. 539545.

Burakov, D.V. (2014d). Sources of Credit Cyclicity: A Theoretical Literature Overview. Review of European Studies, 6(1), pp. $151-159$.

Cunningham, W. J. (1911). Scientific Management in the Operation of Railroads. Quarterly Journal of Economics, 25 (3), pp. $539-562$.

Dewey, D. R., Shugrue, M. J., (1922). Banking and Credit: A Textbook for Colleges and Schools of Business Administration, New York: Ronald Press.

Dione, G. (2013). Risk Management: History, Definition and Critique, CIRRELT, 17.

Haldane, A. (2010). Curbing the Credit Cycle. Speech presented at the Columbia University Center on Capitalism and Society Annual Conference, New York.

Kavanaugh, Th. J. (1921). Bank Credit Methods and Practice, New York: Bankers Publishing Co.

Rötheli, T. (2013). Innovations in Banking Practices and the Credit Boom of the 1920s. Business History Review, 87(2), pp. $309-327$.

Taleb, N.(2009). Report on The Risks of Financial Modeling, VaR and the Economic Breakdown. Report presented on Committee on Science, Space and Technology, 9.

Tversky, A., Kahneman, D. (1974). Judgment under uncertainty: Heuristics and biases, Science, 185, pp. 1124-1130.

Tversky, A., Kahneman, D. (1981). The Framing of Decisions and the Psychology of Choice, Science, 211(4481), pp. 453-458. 